\title{
LUNG BIOPSY IN MITRAL STENOSIS
}

\author{
BY \\ J. B. ENTICKNAP \\ From the Department of Pathology, Guy's Hospital Medical School, London
}

(RECEIVED FOR PUBLICATION AUGUST 27. 1952)

The recent development of intrathoracic operations upon patients with mitral stenosis has provided an opportunity to study by biopsy the changes in the hearts and lungs of these patients at a time when, although the disease is fully established, the general condition is still good. Since, in addition, the specimens are fixed immediately, all suspicion that the appearances seen are terminal or autolytic is removed. As these patients all undergo cardiac catheterization it is also possible to correlate some of the histological features with the functional disturbances. This paper deals with an investigation of lung biopsies along these lines.

\section{Materials and Methods}

The main material was the tips of the lingular segments of the left upper lobes of 32 patients with mitral stenosis. All had pulmonary hypertension but no clinical evidence of acute rheumatism at the time of biopsy. Positive pressure respiration was used during the operations. The specimens were fixed in neutral formol saline and embedded in $58^{\circ}$ C. paraffin so that most of the bronchi and vessels were cut transversely. Some serial sections were made and all were stained by the methods previously cited (Enticknap, 1953). In a few frozen sections no excess of fat was observed.

The ratio of the diameter of the arterial lumina to the thickness of their walls was obtained by a method modified from Kernohan, Anderson, and Keith (1929). Six measurements were made on each vessel in sections stained with haemalum and eosin: two of the lumen at right angles to each other and four of the thickness of the wall, exclusive of adventitia, at the points where the lumen diameters intersect it. Ratios were obtained for the largest artery in each section and for the arterioles by taking the mean of those for the first five between 50 and $150 \mu$ in diameter that were encountered. Care was taken to avoid false thickenings if an arteriole cut slightly obliquely had to be measured.

One case has been excluded from the analysis of vascular changes because the lingula had been the site of an infarct. In the other specimens the changes were found to be uniformly distributed. No comparable control material was available.

In addition I will refer to one specimen taken after death, because it is from the only patient 음 showing widespread necrotizing arteriolitis for $\rightarrow$ whom the pulmonary blood pressure is known.

J. G., aged 23 years, had mitral stenosis for 10 years. He died during what was probably a recurrent attack of acute rheumatism. Thirteen weeks before death the pulmonary arterial pressure was $104 / 64$ and the $\vec{\bullet}$ " pulmonary capillary pressure" $38 / 28$, values about $\stackrel{\mathcal{G}}{\omega}$ $60 \%$ above those recorded 18 months before. The E.S.R. was $51 \mathrm{~mm}$. in one hour (Westergren) and an electrocardiogram showed variable heart block with Wenckebach's phenomenon.

\section{Results}

Most of the sections were divided into two or three parts by septa, one of which was often forked and in which ran the large veins. Only about half the specimens had an obvious main artery, but in all it was possible to identify by its?용 parabronchial position some medium-sized branch of the pulmonary artery; their mean diameter. exclusive of adventitia, was $357 \mu$. I did not 8 find it difficult to distinguish arteries from veins, but no means of separating the former into bron-o chial and pulmonary varieties was discovered. It $\supset$ is likely, however, that the bronchial arteries? terminate at the respiratory bronchioles (Miller. 1947). Since cartilage was rare in these sections it. is improbable that they contained any bronchial 0 arteries greater than $50 \mu$, in which event all vessels N్ల of this size measured belonged to the lesser circulation.

\section{Changes in the Intrapulmonary Blood Vessels. -} Hypertrophy in the arteries and arterioles was. diagnosed by simple microscopical inspection in 11 cases. There was a uniform increase in thick $-\frac{\text { Oे }}{D}$ ness, usually of the media, although in some there@ was fibroblastic thickening of the intima. Sclerosis $\mathbb{\Omega}$ present in six cases, was seen as irregular intimalo thickening, atrophy with fibrous or elastic replace-r 
ment of the media, or gross adventitial thickening. the last usually being associated with one of the other changes. Necrotizing arteriolitis was seen in one ressel in one case with a mean P.A. pressure of $65 \mathrm{~mm}$. Hg. The atrial biopsy showed one possible rheumatic lesion (Enticknap. 1953). but there was no evidence of the so-called rheumatic pneumonia.

Intimal thickening was mostly due to elastosis. but it was not often associated with medial atrophy: it was present in two of the four cases in which intra-arterial thrombi were found. Obliterative endarteritis was seen in one case and endothelial palisading (Crawford and Nassim. 1951) in three others. This change was well marked in the post-mortem case. but in the heart biopsies from the three operation cases no Aschoff cells were

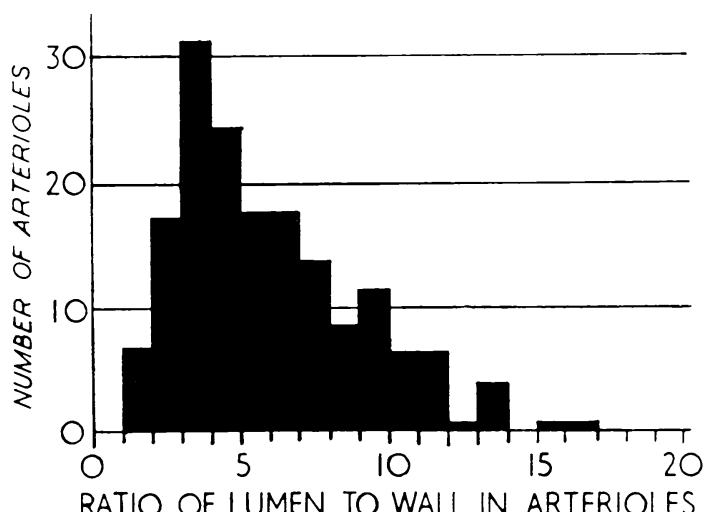

Fk;. 1.- Histogram showing distribution of measurements of lumen to wall ratio in individual arterioles.

seen. No calcification or atheromatous plaques were seen, nor any evidence of a bronchopulmonary anastomotic plexus (Lendrum. Scott, and Park, 1950).

A histogram of the individual ratios (Fig. 1) shows only one significant peak at $4: 1$. and if another were to be drawn it could only be placed at $14: 1$. I have been unable to obtain a range for strictly comparable normal material. but Larrabee. Parker. and Edwards (1949) give 5.5-10.3:1 for necropsy specimens. The main peak must therefore relate to arteriolar measurements. but the latter might relate to those of venules. However, as it is composed of less than $5^{\circ} \circ$ of the total we may conclude that no significant number of vessels other than pulmonary arterioles has been measured.

Thirteen specimens had mean arteriolar ratios of less than 5.5. seven of them showing hypertrophy on simple inspection and four sclerosis. The ratios in the other two cases were 4.8 and 5.4 and the vessels were recorded as qualitatively normal. The other two cases with sclerosis had a mean ratio of 6.3 . and the remaining three with qualitative hypertrophy of 7.4. From this it appears that below a ratio of about $5: 1$ structural changes will be present. that some cases with normal ratios have vessels that appear abnormal. and that these ratios are comparable in biopsy and necropsy specimens.

The correlations between the mean arteriolar ratios and the systolic. mean. and diastolic pulmonary artery pressures. the arterio-capillary pressure gradients, the rise of the mean pressures on exercise and their immediate falls following valvotomy have all been examined. When placed on scatter diagrams the results all show a similar trend. the greater pressures being associated with the smaller ratios. Only one of the correlation coefficients (Table II) is. however. significant. that for the mean pulmonary artery pressure (Fig. 2). the regression equation of which is:

$$
\begin{gathered}
\text { Arteriolar ratio }=21,3 \text { minus mean pulmonary artery prewure } \\
\text { TABLE I } \\
\text { OCCURRENCE OF THE VARIOLS ABNORMALITIES } \\
\text { IN THE PRESENT SERIES }
\end{gathered}
$$

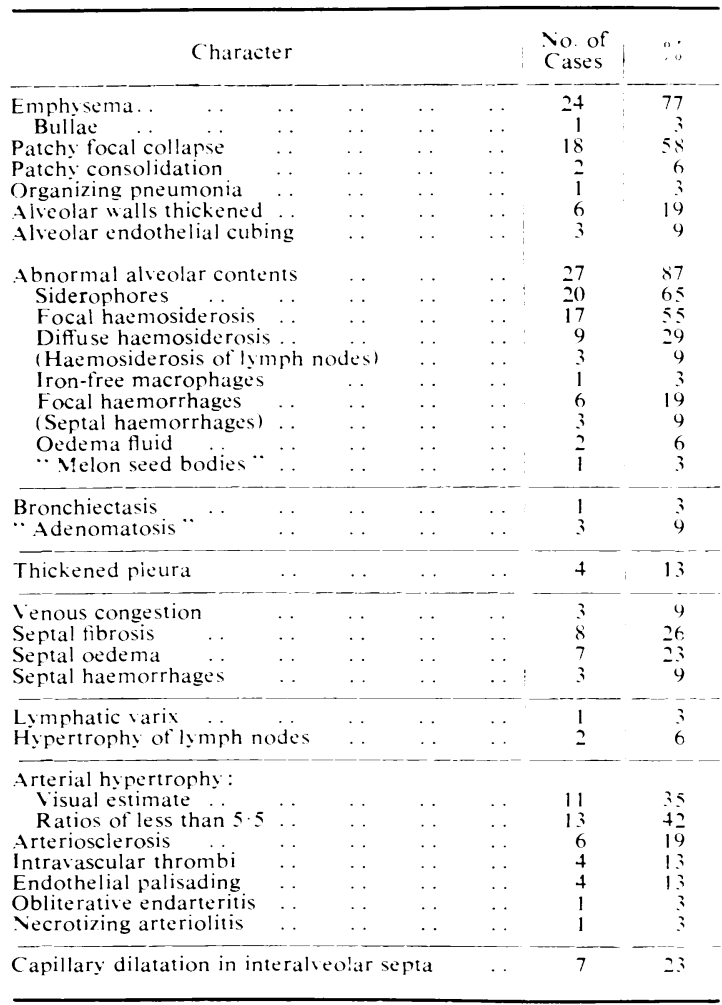


(a)

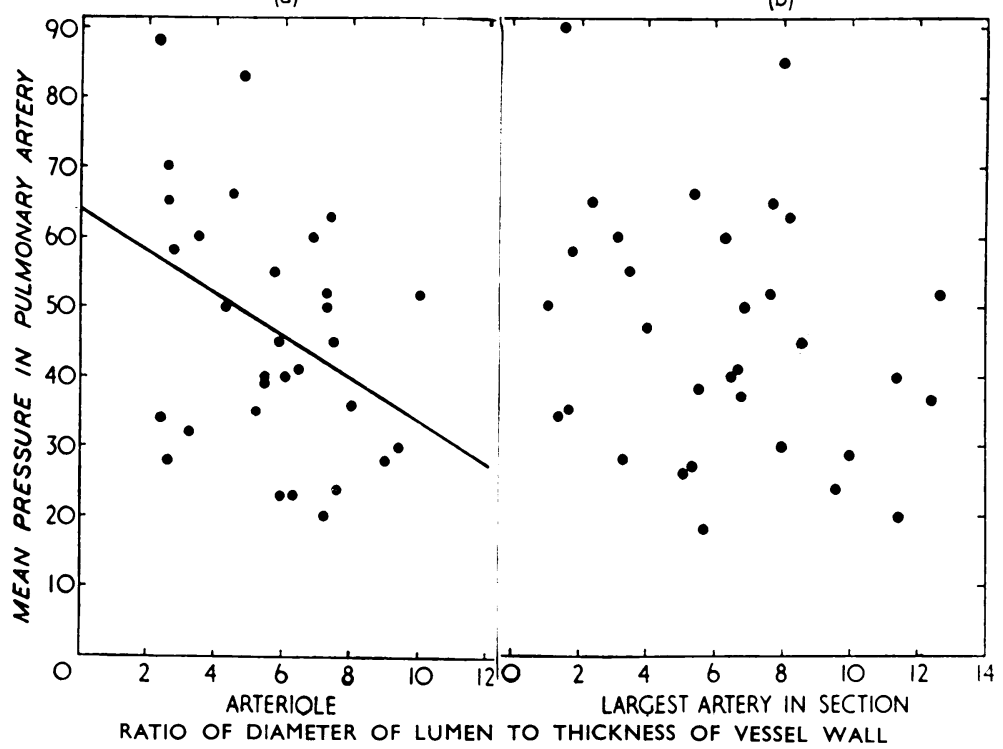

FIG. 2.-(a) Scatter diagram of ratios of diameter of lumen to thickness of arteriolar wall against mean pressure in the pulmonary artery; (b) as above, but for largest artery in section.
TABLE II

CORRELATION COEFFICIENTS AND STANDARD ERRORS FOR COMPARISON BETWEEN VARIOUS PULMONARY BLOOD PRESSURE MEASUREMENTS AND LUMEN/WALL THICKNESS RATIOS OF ARTERIOLES AND LARGEST AVAILABLE PULMONARY ARTERIES

\begin{tabular}{|c|c|c|c|c|c|c|}
\hline \multirow[b]{2}{*}{$\begin{array}{l}\text { Blood Pressure } \\
\text { Measurement }\end{array}$} & \multicolumn{3}{|c|}{ Arterioles } & \multicolumn{3}{|c|}{ Arteries } \\
\hline & $\begin{array}{l}\text { Corre- } \\
\text { lation } \\
\text { Coeff- } \\
\text { cient } \\
\quad r\end{array}$ & S.E. . - & No. & $\begin{array}{c}\text { Corre- } \\
\text { lation } \\
\text { Coeffi- } \\
\text { cient } \\
r\end{array}$ & S.E. & No. \\
\hline $\begin{array}{l}\text { Systolic P.A. pressure } \\
\text { Mean P.A. pressure } \\
\text { Diastolic P.A. pres- }\end{array}$ & $\begin{array}{r}-0 \cdot 33 \\
-0.38\end{array}$ & $\begin{array}{l}0 \cdot 18 \\
0 \cdot 18\end{array}$ & $\begin{array}{l}30 \\
31\end{array}$ & $\begin{array}{c}0.29 \\
-0.23 *\end{array}$ & $\begin{array}{l}0 \cdot 19 \\
0 \cdot 18\end{array}$ & $\begin{array}{l}28 \\
30\end{array}$ \\
\hline $\begin{array}{l}\text { sure } \\
\text { Arterio-capillary pres- }\end{array}$ & $-0 \cdot 19$ & $0 \cdot 18$ & 30 & $0 \cdot 33$ & $0 \cdot 19$ & 28 \\
\hline $\begin{array}{l}\text { sure gradient } \\
\text { Rise of mean P. } \ddot{A} \text {. }\end{array}$ & $-0 \cdot 18$ & $0 \cdot 21$ & 23 & - & - & - \\
\hline $\begin{array}{l}\text { pressure on exercise } \\
\text { Immediate fall in } \\
\text { pressure in P.A. } \\
\text { following valvo- } \\
\text { tomy }\end{array}$ & -0.29 & $0 \cdot 20$ & 25 & - & - & 一 \\
\hline tomy $\quad \cdots \quad \ldots$ & $-0 \cdot 28$ & 0.21 & 23 & $-0 \cdot 04$ & $0 \cdot 22$ & 22 \\
\hline
\end{tabular}

* This figure was checked by showing that no significant difference exists between the means of the pressures of the cases with normal
and those with abnormal ratios (difference $6.4 \mathrm{~mm}$. Hg; S.E. \pm 7.7 ).

The ratios for the largest arteries in the sections gave even less close correlations (Table II), but that between them and the arterioles is highly significant $(r=+0.51$, S.E. $= \pm 0.18)$, the former being slightly smaller $(1: 1.1)$.

The capillaries in the inter-alveolar septa were dilated in seven cases, but the mean arterial pressure in this group was not significantly higher than in the remainder $(49 \mathrm{~mm}$. $\mathrm{Hg}$; difference $5 \mathrm{~mm}$., S.E. \pm 7 ). Only one of these seven cases had abnormal arterioles and the $\ddot{\Rightarrow}$ mean ratio for the group was $\stackrel{0}{9}$ 7.5.

Pulmonary veins were dilated in three cases, but their $\frac{\bar{m}}{\vec{D}}$ mean pressure $(57 \mathrm{~mm} . \mathrm{Hg}) \stackrel{\varnothing}{\varrho}$ was not significantly higher $\stackrel{\&}{\infty}$ than that of the other patients $\vec{\circ}$ (difference $13 \mathrm{~mm}$. $\mathrm{Hg}$, S.E. \pm 10 ).

Parenchymal Changes. $-\frac{\text { S }}{\text { S }}$ The alveolar walls were ? thickened by increase in elastic tissue or the presence of collagen in six cases, and in four there was cubing of the alveolar lining cells. No other features of the socalled rheumatic pneumonia were seen and I could not identify the reduplication of the basement membrane described by Parker and Weiss (1936).

Haemosiderin-containing macrophages were present in the alveoli in 20 cases $(65 \%)$, in focal aggregations (Lendrum, 1950) in 17 cases, and distributed diffusely in nine. The term siderophores is preferred to the siderophages of Lendrum, since the cells probably ingest red corpuscles and not haemosiderin. Thus in six cases focal alveolar haemorrhages were present, in one of which some bright yellow intracellular pigment, probably bilirubin, as well as siderophores were seen. The appearances made it improbable that these were operative haemorrhages. In two other cases septal haemorrhages and in one macrophages devoid of pigment were seen. None of these changes was obviously correlated with other phenomena.

\section{Discussion}

This investigation was performed (1) to confirm that appearances in necropsy material are also present before the patient has been in cardiac failure or has died from mitral stenosis; (2) to evaluate biopsy of the lingula as an aid to prognosis: (3) to relate the vascular changes to the disordered physiology of this disease. The results show that both vascular and parenchymal abnormalities are frequently present in well-compensated patients (Baker, Brock, Campbell, and Wood, 1952), but a knowledge of them is of little value in managing individual cases.

Vascular Changes.-Dilatation of septal capillaries has long been regarded as characteristic of 
mitral stenosis, but though found in these biopsies it did not correlate with either elevated blood pressure or vascular abnormalities. Its absence from lungs with abnormal arteries suggests that changes that tend permanently to restrict the lumina of the latter in some way prevent its development. Should this be so it implies that the rise of pressure is initiated on the right side, for a pre-capillary block can only prevent their dilatation if the raised pressure comes from the arterial side but not that secondary to back pressure from the left atrium. The findings are, however, compatible with the hypothesis that the vascular changes are the effect and not the cause of the hypertension.

Sclerotic and hypertrophic vascular changes were frequently present and both caused diminished lumen to wall ratios. No common physiological differences distinguished the cases with the two forms of abnormality, so in calculating the coefficients of correlation they have been considered together. In assessing the significance of these coefficients the experimental errors of the data from which they are derived require consideration. Since each arteriolar ratio depends upon 30 separate micrometric operations whereas that for the largest artery is derived from only two diameters, and since the mean pressures are less liable to error than individual systolic or diastolic readings, it is not surprising that the only significant correlation was that of the arteriolar ratios with the mean pressure. A significant coefficient does not, of course, indicate a causative relationship but does suggest that some mechanism exists by which changes in the one are dependent on those in the other; discovery of the probable existence of such links is the first step to elucidation of their nature. The relationship between these two quantities may, without serious inaccuracy, be represented by the simpler formula of

$$
\text { Arteriolar ratio }=21-\frac{1}{3} \text { (mean pressure) }
$$

so that vascular changes will probably be present in all patients who have a mean pulmonary artery pressure of more than $50 \mathrm{~mm}$. $\mathbf{H g}$.

The three cases with the low mean pressures and low ratios that appear together near the lower lefthand corner of Fig. 2 also showed a tendency to remain associated in the other spot diagrams. Reexamination of these three paradoxical cases confirmed the findings, but there is no other common feature that would, at present, justify divorcing these cases from the rest of the group.

Only four of these patients have so far undergone catheterization some months after operation, but the results do not suggest that the pressure difference over this period correlates any better with the arteriolar changes than does that observed at operation.

Other degenerative vascular changes were uncommon. Hyalinization of arteriolar walls was not seen in any specimen and in only one was arteriolar necrosis present. This virtual absence of two of the lesions characteristic of hypertension in systemic vessels merits discussion in view of the high pulmonary pressures recorded in these patients.

The absence of hyalinization from hypertrophied vessels, some of which had ratios of less than $1: 1$, and one, indeed, of $1: 0.14$, makes it certain that ischaemia resulting from medial thickening is not the sole cause of this degeneration. Neither does the hypothesis of Duguid and Anderson (1952), that it is due to mural deposition and incorporation of circulating substances, allow of any more acceptable explanation, for thrombus formation without any hyalinization was present in four cases and the sclerotic changes had probably originated in thrombi (Harrison, 1948 ; Muirhead and Montgomery, 1951). Again, the absence of hyalinization cannot be ascribed to the shorter duration of pulmonary as opposed to systemic hypertension, for in several of these subjects it had persisted for a time quite comparable to that required for degeneration of the systemic arterioles in benign hyperpiesis. Since no aetiological explanation for this peculiarity of the diseased pulmonary circulation is apparent, the possibility that its arterioles differ fundamentally from the comparable systemic vessels requires consideration.

Brenner (1935) and other authors lay stress on microstructural differences but these are not striking and may well be the result of the lower pressures to which these vessels are normally subject. Now, as it is virtually certain that systemic arteriolar hyalinization is dependent upon hypertension, the findings in this series of pulmonary hypertensive subjects suggest that it may depend more upon the absolute level than on the amount of increase, for the highest pressure in these subjects $(120 / 95)$, although $300 \%$ above normal, would not be excessive in the greater circulation. In this interpretation of the relationship of hyalinization to hypertension its absence from the pulmonary arterioles in these biopsies is to be expected and it is unnecessary to postulate any peculiarities in these vessels. We may therefore conclude that this study does not provide any reason for so doing, and, since pressures in excess of $120 \mathrm{~mm} . \mathrm{Hg}$ are uncommon in any form of pulmonary hypertension, it is improbable that any will appear in the future. 
The highest mean pressures in the two cases with necrotizing arteriolitis were 65 and $76 \mathrm{~mm}$. $\mathrm{Hg}$ respectively and were lower by 23 and $12 \mathrm{~mm}$. than the highest in the series as a whole. The reading of $76 \mathrm{~mm}$. $\mathrm{Hg}$ was, however, made 13 weeks before death and the pressure may have suddenly or progressively risen during that period. Since necrotizing arteriolitis is uncommon in biopsy specimens and few cases coming to necropsy will have been catheterized within a few days of death, these two cases may serve as a basis for speculation. In the post-mortem case it was thought clinically that subacute rheumatism had been present during the last few months of life; examination showed fibrinous vegetations on the tricuspid valve and the changes of so-called rheumatic pneumonia. Histologically there were some foci of mononuclear cells in the myocardium, some fibrinoid change in collagen, and an occasional giant cell, but no complete Aschoff bodies were seen. It was concluded that this patient had died during an exacerbation of rheumatic infection, so it is probable that the arteriolar lesions were not solely due to excessive strain but to a combination of this with the infective process. In any event, necrotizing lesions were seen in a patient whose degree of pulmonary hypertension would not, without further rise, have accounted for them. Unfortunately the operation case is no easier to interpret, for while there was no clinical evidence of acute rheumatism, the histology of the atrial biopsy did suggest that possibility. On the other hand, Symmers reports a case (case 1, Symmers, 1952) in which there was no suspicion of rheumatic disease at any time during life ; he refers to similar published cases, but in none were the pulmonary pressures recorded. While these considerations do not decide the cause of this lesion they make it probable that some of the highest pulmonary pressures seen are alone insufficient and suggest that some other explanation may be found in cases showing it.

Experimental pulmonary arteriosclerosis (Harrison, 1948) is histologically very similar to some of the sclerotic lesions seen, but the fact that these were present in only four cases is in conformity with the conclusion of Heard (1952) that the $\vec{\Rightarrow}$ changes resulting from the organization of $\stackrel{5}{?}$ autochthonous thrombi are seldom large.

\section{Summary}

The parenchymal changes seen in the lingulae $\stackrel{\mathbb{Q}}{\varrho}$ removed from 32 patients with mitral stenosis at the time of valvotomy are tabulated.

The vascular changes are described and have been correlated with the measurements of pul- $\vec{\omega}$ monary blood pressure.

There is a significant correlation between the $\frac{\overrightarrow{0}}{0}$ height of the mean pressure in the pulmonary artery and the thickness of the arteriolar walls, $\vec{\infty}$ the higher the pressure the thicker being the $\stackrel{\infty}{\oplus}$ vessels.

Sclerotic changes in the arteries are less com- mon than hypertrophy, but the significance of both T⿱ changes in relation to pulmonary hypertension $\frac{0}{2}$ appears to be similar.

Hyaline arteriolar changes were not seen in the biopsy specimens, and only one showed arteriolo- $\vec{\oplus}$ necrosis, although some very high pressures were recorded. The pathogenesis of these changes is 0 discussed.

I am grateful to Drs. H. E. Holling and A. Venner $\bar{\partial}$ for permission to use their cardiac-pressure recordings $\underset{\mathbb{O}}{\not}$ and for advice in the interpretation of them, and also $\mathbb{Q}$ to Professor G. Payling Wright for help with the $\overrightarrow{\vec{D}}$ manuscript and presentation of the statistics. The $\frac{0}{3}$ operations were performed in the Thoracic Surgical Unit under Mr. R. C. Brock.

RFFERFNCES

Baker, C., Brock. R. C. Campbell. M., and Wood, P. (1952). Brit med. J., 1,1043

Brenner, O. (1935). Arch. intern. Med., 56, 211

Crawford T and Nassim, J. R (1951), J Path. Bact. 63. 619

Duguid, J. B., and Anderson, G. S. (1952). Ibid., 64, 519.

Duguid, J. B., and A (1953). Brit. Heart J., 15, 37.

Enticknap. J. B. (1953). Brit. Heart J., 15, 37.

Harrison, C. V. (1948) J. Path. Ba
Heard, B. E. (1952). Ibid.. 64, 13.

Kernohan, J. W. Anderson. E. W., and Keith. N. M. (1929). Arch. 음 intern. Med., 44, 395.

Larrabee, W. F., Parker, R. L., and Edwards, J. E. (1949). Proc Mayo Clin. 24, 316

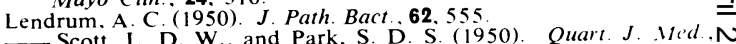
Scott. L. D.

Miller, W. S. (1947). The Lung, 2nd ed. Thomas, Springfield. III.

Muirhead, E. E., and Montgomery, P. O'B. (1951). Arch. Path. N Chicago, 52, 505

Parker, F. and Weiss, S. (1936). Amer. J. Path. 12. 573

Symmers, W. St. C. (1952). Journal of Clinical Pathology, 5. 36. 